new German ventricular assist device. Thorac Cardiovasc Surg 1994;42:136-40.

2. Eilers R, Harbott P, Reul H, Rakhorst G, Rau G. Design improvements of the HIA-VAD based on animal experiments. Artif Organs 1994;18:438-73.

3. Tandler R, Deng MC, Schmid C, Scheld HH. Novacor LVAD bridge to transplantation in peripartum cardiomyopathy. Eur J Cardiothorac Surg. In press.
4. Scheld HH, Hammel D, Schmid C, Weyand M, Deng MC, Möllhoff $\mathrm{T}$, et al. Beating heart implantation of a wearable Novacor left-ventricular assist device. Thorac Cardiovasc Surg 1996;44:62-6.

5. Weyand M, Hammel D, Hoffmeier A, Loeher A, Frye K, Kerber $\mathrm{S}$, et al. Erfahrungen mit dem tragbaren Links-HerzUnterstützungssystem NOVACOR N 100. Transplantationsmedizin 1994;6:245-52.

\title{
INTRAOPERATIVE PATENCY CONTROL OF ARTERIAL GRAFTS IN MINIMALLY INVASIVE CORONARY ARTERY BYPASS GRAFT OPERATIONS BY MEANS OF ENDOSCOPIC THERMAL CORONARY ANGIOGRAPHY
}

Volkmar Falk, MD, Anno Diegeler, MD, Thomas Walther, MD, Hugo Kitzinger, Jacques A. M. van Son, MD, PhD, Rüdiger Autschbach, MD, PhD, and Friedrich W. Mohr, MD, PhD, Leipzig, Germany

Intraoperative patency control of internal thoracic artery (ITA) grafts in minimally invasive direct coronary artery bypass graft (MIDCAB) operations is hampered by a limited surgical access. A new method to intraoperatively assess graft patency was developed with the use of an endoscopic thermal scanner that can be operated through a port or inserted directly through a small thoracotomy incision.

Methods. MIDCAB operations with the ITA to graft the left anterior descending coronary artery (LAD) were performed in six male patients (aged 52 to 68 years) with isolated disease of the LAD. Four patients had a history of single or multiple percutaneous angioplasties. Left ventricular function was within normal limits in all patients (ejection fraction $>50 \%$ ). Patients were anesthetized and placed in a supine position. Through a small anterolateral thoracotomy $(6$ to $8 \mathrm{~cm})$ in the fourth intercostal space, the ITA was harvested. Two patients underwent cardiopulmonary bypass with endoaortic clamping and cardioplegic arrest by means of the Port-Access System (Heartport, Inc., Redwood City, Calif.). ${ }^{1}$ In the other four patients we operated on

From the Department of Cardiac Surgery, Heartcenter, University of Leipzig, Leipzig, Germany.

Received for publication March 11, 1997; accepted for publication March 17, 1997.

Address for reprints: Volkmar Falk, MD, Klinik für Herzchirurgie, Universität Leipzig, Herzzentrum, Russenstraße 19, 04289 Leipzig, Germany.

J Thorac Cardiovase Surg 1997;114:507-9

Copyright (C) 1997 by Mosby-Year Book, Inc.

0022-5223/97 $\$ 5.00+0 \quad \mathbf{1 2 / 5 4 / 8 2 0 9 5}$ the beating heart with temporary LAD occlusion and local ventricular wall immobilization using the CTS system (Cardio Thoracic Systems, Cupertino, Calif.). ${ }^{2}$ After completion of the distal anastomosis and before release of the vascular clamp, an endoscopic thermal scanner (Infracam, Inframetrics, North Billerica, Mass.) was introduced through the thoracotomy incision. The scanner based on a platinum silicon (PtSi) focal plane array detector $(256 \times 256$ elements $)$ operates at a wavelength of 3.4 to $5.0 \mu \mathrm{m}$ (mid-infrared spectrum) with a spatial resolution of $0.6 \mathrm{mrad}$. A $30 \mathrm{~cm}$ endoscope with an indium antimony ( $\mathrm{InSb}$ ) lens allows the scanner to operate through a $10 \mathrm{~mm}$ port. After placement of the endoscope above the surface of the heart and after local topical cooling, the vascular clamp on the ITA graft was released. The thermal gradient generated by the inflow of warm blood through the graft delineated the anastomosis and the distal vascular bed. The resulting heat picture was transformed online into an angiographic picture on a conventional video screen. In all patients graft flow was also confirmed by transittime Doppler-flow measurements (Transonic Systems Inc., Ithaca, N.Y.). All patients underwent a second angiogram before discharge (postoperative days 3 to 6).

Results. All operations were uneventful. Median ITA takedown was 33 minutes and median operation time was 117 minutes. Placement of the endoscope was performed through the thoracotomy incision in all cases. Fig. 1 shows a typical intraoperative thermal angiogram of an ITA graft to the LAD that was performed on the beating heart. Before release of the vascular clamp, the surface of the heart shows a homogeneous temperature distribution. The forceps indicates the site of anastomosis (Fig. 1,a). After release of the vascular clamp, thermal coronary angiography shows immediate antegrade perfusion of the LAD, as well as retrograde filling of a first diagonal branch, documenting graft and anastomotic patency. Thermal 

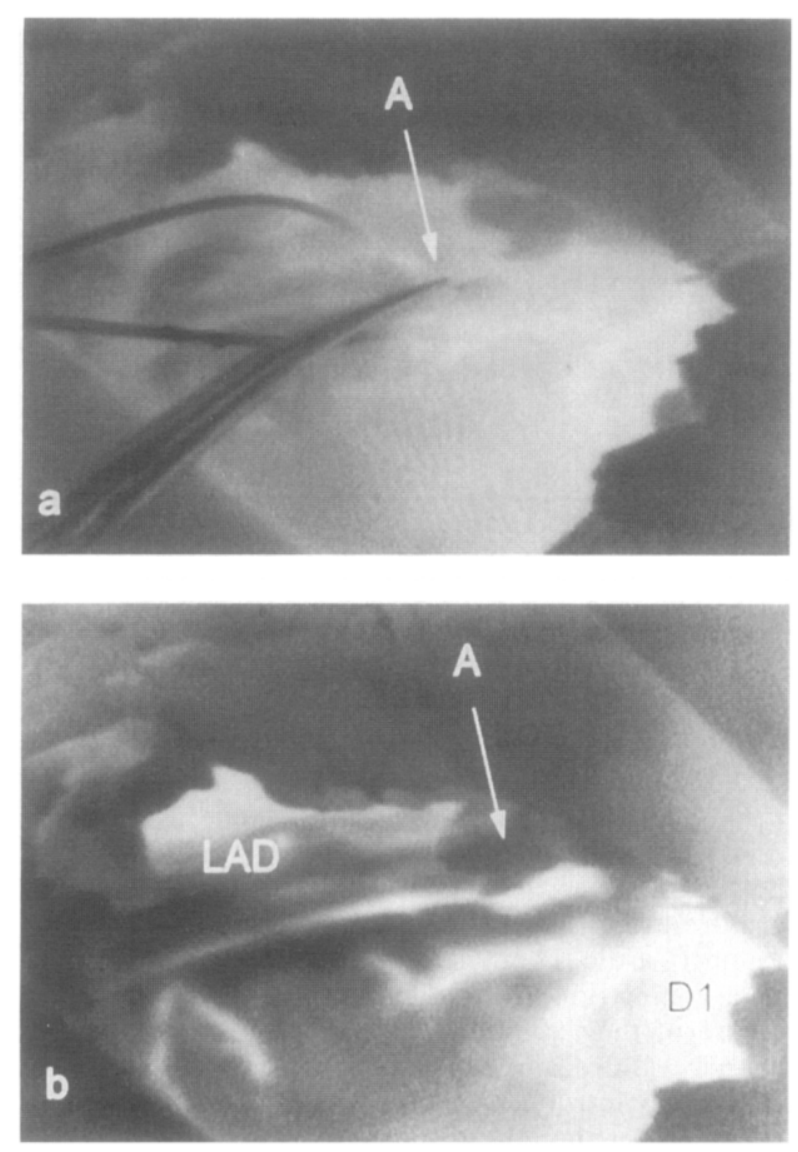

Fig. 1. Intraoperative endoscopic thermal coronary angiogram of an ITA graft to the LAD during minimally invasive surgery on the beating heart. a, Homogeneous surface temperature of the heart before release of the vascular clamp after local topical cooling. Forceps indicates level of the anastomosis $(A)$. $\mathbf{b}$, After release of the vascular clamp, there is perfusion of the distal LAD as well as retrograde perfusion of a first diagonal branch (D1).

coronary angiography revealed patency of the ITA graft in all six patients. Median graft flow as measured by transit-time Doppler ultrasonography was $46 \mathrm{ml} / \mathrm{min}$ ( 32 to $70 \mathrm{ml} / \mathrm{min}$ ). No patient showed signs of myocardial ischemia in the perioperative period (normal electrocardiogram, no significant elevation of cardiac enzymes). Median intubation time was 10 hours. ICU stay and time of hospitalization were 1 day and 8 days, respectively. On postoperative angiography, all ITA grafts were patent and showed good runoff.

Discussion. Control of intraoperative graft patency is important to avoid the catastrophic consequences that can be caused by ITA graft failure. Especially in MIDCAB operations, in which grafting is technically more demanding and access to the heart is limited, there is a need for intraoperative quality control. Thermal coronary angiogra- phy has been developed for intraoperative noninvasive testing of anastomotic patency in conventional coronary artery bypass graft operations. ${ }^{3}$ Thermal coronary angiography has been shown to correctly identify anastomotic failures during the operation and has led to graft revision in routine coronary artery operations. ${ }^{4,5}$ The method not only provides a noninvasive angiographic picture of the graft and the attached coronary artery but also reflects graft flow by the velocity of the induced temperature changes. Although conventional thermal imaging has been used to document ITA graft flow to the LAD in a MIDCAB procedure, the obtained images were of poor quality and did not visualize the vascular bed completely. ${ }^{6}$ Because of the limited surgical access, ceiling or tripod-mounted thermal imaging systems cannot be positioned accurately. The endoscopic thermal scanner that can be directly placed through the thoracotomy incision or through a separate port is therefore far superior. The system allows for optimal imaging in the region of interest. After brief topical cooling, heat contrast was sufficient to demonstrate graft flow even on the beating heart. Intraoperative flow measurement, as well as postoperative angiography, confirmed the results of thermal coronary angiography.

As a noninvasive method, thermal coronary angiography does not require any manipulation of the graft. As again demonstrated in this series, intraoperative flow measurements using transit-time Doppler ultrasonography are awkward in MIDCAB procedures. Because of the limited access, positioning of the flow probe is difficult and also requires skeletonizing of the pedicle, which can be potentially harmful. Furthermore, the Doppler method only provides a flow curve, whereas thermal coronary angiography visualizes the complete vasculature in an angiographic fashion. On the beating heart, generation of a temperature gradient by short-term local topical cooling (sponge soaked in saline solution) immediately before thermal imaging improves image quality. A digital substraction method to further enhance contrast is currently under investigation. If applied during a closed chest technique with cardioplegic cardiac arrest (Port-Access method), endoscopic thermal coronary angiography provides even higher quality images. In conclusion, endoscopic thermal coronary angiography is a useful adjunct in MIDCAB surgery. It allows for a no-touch intraoperative graft patency control.

\section{REFERENCES}

1. Stevens JH, Burdon TA, Peters WS, Siegel LC, Pompili MF, Vierra $\mathrm{MA}$, et al. Port-access coronary artery bypass grafting: a proposed surgical method. J Thorac Cardiovasc Surg 1996;111:567-73.

2. Boonstra PW, Grandjean JG, Mariani MA. Improved method for direct coronary grafting without CPB via anterolateral small thoracotomy. Ann Thorac Surg 1997;63:567-9.

3. Mohr FW, Matloff J, Grundfest W, Chaux A, Kass R, Blanche $\mathrm{C}$, et al. Thermal coronary angiography: a method for assessing graft patency and coronary anatomy in coronary bypass surgery. Ann Thorac Surg 1989;47:441-9. 
4. Mohr FW, Falk V, Krieger H, Likungu J, Abu Aisha N, Coppola $\mathrm{R}$, et al. IMA-graft patency control by thermal coronary angiography during coronary bypass surgery. Eur J Cardiothorac Surg 1991;5:534-41.

5. Falk V, Walther T, Philippi A, et al. Thermal coronary angiography for intraoperative patency control of arterial and saphenous vein coronary artery bypass grafts: results in 370 patients. J Card Surg 1995;10:147-60.

6. Emery RW, Emery AM, Flavin TF, Nissen M, Mooney MR, Arom KV. Revascularization using angioplasty and minimally invasive techniques documented by thermal imaging. Ann Thorac Surg 1996;62:591-3.

\title{
TROPONIN I RELEASE DURING MINIMALLY INVASIVE CORONARY ARTERY SURGERY
}

\author{
I. Birdi, FRCS, M. Caputo, MD, J. A. Hutter, FRCS, A. J. Bryan, FRCS, and G. D. Angelini, FRCS, \\ Bristol, United Kingdom
}

Revascularization of the left anterior descending artery (LAD) without cardiopulmonary bypass through a left anterior small thoracotomy (LAST) ${ }^{1}$ is increasing in popularity. This has been driven partly by current trends toward cost containment, ${ }^{2}$ despite the fact that the effectiveness of the surgical procedure both in terms of early and long-term outcome are still under evaluation. One concern is the potential risk of ischemic damage to the warm, metabolically active myocardium during occlusion of the LAD. To investigate this further, we measured troponin I, a highly specific marker for the detection of myocardial injury, ${ }^{3}$ in 14 selected patients ( 13 men, mean age 58 years) undergoing LAD revascularization via the LAST operation. These were compared with a control group of 14 patients (12 men, mean age 57 years) undergoing myocardial revascularization of one or two arteries with the use of normothermic cardiopulmonary bypass and warm blood cardioplegia. All patients underwent elective operations and had well-preserved left ventricular function. Blood samples were collected for troponin I estimation before the operation and $4,12,24,36$, and 48 hours after the operation.

The two groups were similar with respect to preoperative characteristics. No patient had clinical or electrocar-

From the Bristol Heart Institute, University of Bristol, Bristol Royal Infirmary, Bristol, United Kingdom.

Received for publication April 1, 1997; accepted for publication April 9, 1997.

Address for reprints: Gianni D. Angelini, FRCS, British Heart Foundation, Professor of Cardiac Surgery, Bristol Heart Institute, Bristol Royal Infirmary, Bristol BS2 8HW, United Kingdom.

J Thorac Cardiovase Surg 1997;114:509-10

Copyright (C) 1997 by Mosby-Year Book, Inc.

$0022-5223 / 97 \$ 5.00+0 \quad \mathbf{1 2 / 5 4 / 8 2 6 7 8}$ diographic evidence of perioperative myocardial infarction. Cardiopulmonary bypass time in the control group was $49 \pm 8$ minutes during which time a mean of $1.5 \pm 0.5$ distal anastomoses were performed. The ischemic times in the control and LAST groups were $24 \pm 5$ minutes and $37 \pm 8$ minutes, respectively. Preoperative troponin I concentrations were undetectable in both groups. In the control group, a significant rise in troponin I concentrations was observed 4 hours after the operation; the peak occurred at 12 hours, and the concentration remained significantly higher than preoperative levels even at 48 hours $(p<0.006)$. In the LAST group, a small but significant rise in troponin I concentration was noted at 4 hours $(p<0.02)$, but the levels were considerably lower

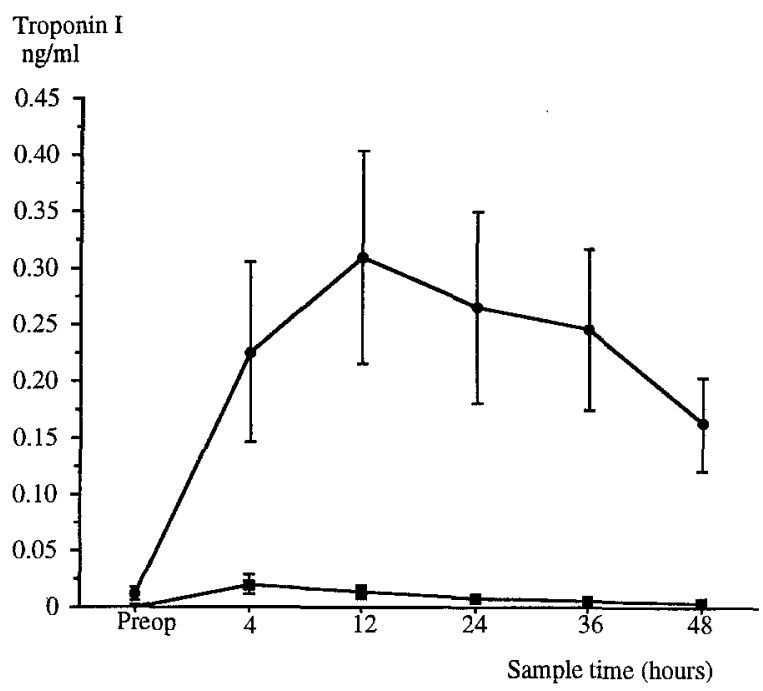

Fig. 1. Troponin I release after coronary artery surgery. 口, Conventional CABG; $\bullet$, last operation. 